\title{
COBERTURA DA PULVERIZAÇÃO E MATURAÇÃO DE FRUTOS DO CAFEEIRO COM ETHEPHON EM DIFERENTES CONDIÇÕES OPERACIONAIS ${ }^{(1)}$
}

\author{
FÁBIO SCUDELER ${ }^{(2,6)}$; CARLOS G. RAETANO ${ }^{(3)}$; DEMÉTRIUS DE ARAÚJO(2,5); \\ FERNANDO C. BAUER ${ }^{(4)}$
}

\begin{abstract}
RESUMO
A arquitetura trapezoidal do cafeeiro, dependendo da variedade, constitui sério entrave à aplicação de agroquímicos que precisam atingir diretamente o alvo, nesse caso, os frutos. Com o propósito de avaliar e comparar a distribuição e o depósito de uma solução traçadora, bem como a eficiência do regulador de crescimento ethephon na maturação dos frutos do cafeeiro, quando aplicados com diferentes pulverizadores e condições operacionais, foram desenvolvidos dois experimentos em plantio comercial dessa cultura. O uso de papel hidrossensível e de uma escala visual de notas para diferentes níveis de fluorescência emitida pela solução traçadora possibilitaram a avaliação da distribuição da pulverização. A avaliação quantitativa dos depósitos do traçador foi feita através de espectrofotometria e a eficiência do ethephon, pela porcentagem relativa de frutos verdes e cereja nos diferentes tratamentos. Maiores depósitos na parte inferior das plantas foram obtidos com o turboatomizador Arbus 400, equipado com as pontas HC-02 e JA-2. Melhor distribuição da pulverização foi obtida em frutos localizados na parte inferior e frontalmente ao direcionamento da pulverização. Com o equipamento Arbus 400, equipado com pontas HC-02, em menores pressões de trabalho, pode-se constatar maiores porcentagens de frutos maduros, porém não foi suficiente para reduzir o percentual de furtos verdes além dos $20 \%$, aos 59 dias após a aplicação do ethephon.
\end{abstract}

Palavras-chave: tecnologia de aplicação, depósito, regulador de crescimento, traçador, café.

\section{ABSTRACT \\ SPRAYING COVERAGE AND MATURATION UNIFORMITY WITH ETHEPHON IN COFFEE TREE FRUIT UNDER DIFFERENT OPERATIONAL CONDITIONS}

The coffee tree trapezoidal design has been a serious obstacle to agrochemical use which is supposed to reach the fruits directly. Depending on the coffee variety this problem can become even greater. This experiment aimed to evaluate and compare a tracer solution distribution and deposition as well as to verify the efficacy of the ethephon growth regulator on coffee fruit ripening. Different operational conditions and sprayers were used. Water-sensitive paper and a visual grade scale used for different fluorescence levels emitted by the tracer solution have enable spraying distribution evaluation. Quantitative evaluation of tracer deposition and ethephon efficacy were carried out through spectrophotometry and

(1) Recebido para publicação em 15 de outubro de 2002 e aceito em 10 de outubro de 2003.

$\left({ }^{2}\right)$ Graduando em Agronomia - Faculdade de Ciências Agronônicas/UNESP.

$\left({ }^{3}\right)$ Departamento de Produção Vegetal-Defesa Fitossanitária - FCA/UNESP, Caixa Postal 237, 18603-970 Botucatu (SP).

$\left({ }^{4}\right)$ Doutorando do curso de Pós-Graduação em Agronomia - Proteção de Plantas - FCA/UNESP.

$\left(^{5}\right)$ Bolsista CNPq.

$\left({ }^{6}\right)$ Bolsista FAPESP. 
relative percentage of unripe and ripe fruits, respectively. A higher deposition in lower canopy was obtained using Arbus 400 air carrier sprayer equipped with HC-02 and JA-2 hollow-cone nozzles. Better spraying distribution was observed in fruits at lower canopy and frontally toward spraying. The highest percentage was obtained using HC-02 nozzle Arbus 400 equipment under lower work pressure, although it was not enough to reduce ripe fruit to less than $20 \%$ following 59 days from ethephon application.

Key words: application technology, air carrier sprayer, ethephon, tracer, coffee tree.

\section{INTRODUÇÃO}

A colheita manual do café (Coffea arabica L.) é operação onerosa, demorada e altamente dependente de mão-de-obra, consumindo entre $30 \%$ e $40 \%$ do custo total de produção. Para reduzir o custo dessa operação, os cafeicultores estão substituindo a colheita manual pela mecanizada, principalmente em plantios de café adensado, no cerrado brasileiro, onde o custo é reduzido até em $60 \%$, com a vantagem de obter um produto de melhor qualidade (KASHIMA et al., 1986). Entretanto, para adotar a colheita mecanizada, é fundamental que a maturação dos frutos seja uniforme, a fim de evitar a necessidade de sucessivos repasses manuais, resultando em elevação de custos para o produtor.

Independentemente da forma de manejo da cultura estima-se que a retenção de frutos na planta, por ocasião da colheita mecânica, represente cerca de $20 \%$ do total dos frutos produzidos. Esses frutos retidos, em sua maioria ainda verdes, são colhidos posteriormente, por ocasião dos repasses, feitos manualmente. Por esse motivo, na tentativa de obter maior uniformidade na maturação dos frutos e, conseqüentemente, diminuir o número de frutos retidos, pesquisas têm sido realizadas com aplicação do regulador de crescimento ethephon (ácido 2-cloro-etil-fosfônico). Dentre os processos fisiológicos afetados pelo etileno destaca-se o aumento da respiração climatérica e conseqüente aceleração da maturação dos frutos (WAREING e PHILlips, 1970).

No entanto, os resultados de pesquisas com ethephon revelam que, para a maturação perfeita, os frutos já devem ter completado ao menos $75 \%$ da maturação antes da aplicação, pois os frutos com menor grau de maturação não amadurecem ou produzem grãos com aparência de maduros, mas com o endosperma sem ainda estar completamente desenvolvido, prejudicando a qualidade do grão, além de não ter efeito benéfico na colheita (RENA e MAESTRI, 1986). Assim, aplicando o ethephon quando o cafeeiro apresentar os frutos completamente desenvolvidos, época em que o endosperma desprende-se da semente, a maturação ocorrerá 15 dias após a aplicação (Mônaco e SondAhL, 1974; CRIsosto et al., 1992) e a colheita pode ser realizada 20 a 30 dias após (MigueL et al., 1975; WINSTON et al., 1992).
A concentração de ácido 2-cloro-etil-fosfônico ou de seus derivados, não deve ultrapassar $1 \mathrm{~g} \cdot \mathrm{L}^{-1} \mathrm{em}$ pulverizações de árvores não sombreadas, aplicados apenas uma vez; concentrações acima desse valor podem resultar em elevada abscisão foliar e outros efeitos fitotóxicos (Mônaco e Sondahl, 1974; Winston et al., 1992).

O contato do produto com os frutos ainda verdes é necessária para uniformizar e acelerar o processo de maturação (SoNDAHL et al., 1974). Entretanto, esse fator depende da eficiência pois o ethephon não é translocado (QuAGGIO et al., 1976).

A necessidade de contato do produto com os frutos representa grande dificuldade, pois para se obter o efeito desejado e preciso colocar o produto em todos os frutos, inclusive naqueles posicionados nas partes mais internas e baixas da planta (saia do cafeeiro). Desse modo, a tecnologia de aplicação se mostra de extrema importância, pois em algumas cultivares de café, a arquitetura da planta pode constituir-se em sério obstáculo à penetração de produtos fitossanitários, devido a características próprias da cultura e maior enfolhamento das plantas, os quais impedem que a calda penetre e atinja os frutos mais internos à copa.

Na literatura, os trabalhos fazem referência à tecnologia de aplicação de forma extremamente superficial, enfatizando somente os resultados de eficiência de controle, normalmente dos insetos-pragas: bichomineiro (Leucoptera coffeellum), broca do café (Hypothemus hampei) ou doenças como a ferrugem (Hemileia vastatrix), não mencionando o volume de calda em alguns trabalhos.

Ainda com relação à tecnologia de aplicação, pode-se afirmar que houve grande desenvolvimento, em se tratando de máquinas e técnicas de aplicação na cultura de cafeeiro, a despeito da pequena importância atribuída a essa ciência no passado.

Portanto, são necessários estudos visando à obtenção de melhores técnicas na aplicação do ethephon, tendo como objetivo final a redução dos custos de colheita. Assim, o objetivo deste trabalho foi avaliar a cobertura da pulverização na cultura do café, com diferentes equipamentos e condições operacionais, associada à avaliação da eficiência do ethephon na uniformidade de maturação dos frutos de café. 


\section{MATERIAL E MÉTODOS}

Dois experimentos foram desenvolvidos, separadamente, em plantio comercial de café (Coffea arabica L.), variedade Catuaí Vermelho (IAC 99), com 4,5 anos de idade, espaçamento de $3,5 \times 1,0 \mathrm{~m}$ e altura média de 2,0 m, localizado na Fazenda Três Irmãos em Botucatu (SP). O primeiro em 24/5/2001, para avaliar a distribuição e os depósitos das pulverizações de solução traçadora com diferentes equipamentos e condições operacionais (Experimento 1); o segundo, em $22 / 6 / 2001$, a ação do ethephon na maturação dos frutos (Experimento 2).
O Experimento 1 foi implantado no delineamento inteiramente casualizado, com sete tratamentos e oito repetições (Tabela 1).

Cada tratamento constituiu-se de três linhas de plantio. Apenas a linha do meio, com 50 plantas $(50 \mathrm{~m})$, foi pulverizada de ambos os lados; as demais linhas foram consideradas como bordadura. Cada parcela foi composta de seis plantas consecutivas na linha de plantio pulverizada.

As avaliações foram realizadas somente em uma planta por parcela, previamente identificada, e as demais, consideradas como bordadura.

Tabela 1. Equipamentos e condições operacionais para avaliar a distribuição e os depósitos de pulverização na cultura do cafeeiro

\begin{tabular}{|c|c|c|c|c|c|c|}
\hline Tratamento & o Equipamento & Tipo de ponta & Pressão & Velocidade & $\begin{array}{l}\text { Volume de } \\
\text { Aplicação }\end{array}$ & Vazão/bico \\
\hline \multirow[b]{2}{*}{1} & & N. ${ }^{o}$ & $\mathrm{kPa}$ & $\mathrm{km} \cdot \mathrm{h}^{-1}$ & L.ha ${ }^{-1}$ & L. $\min ^{-1}$ \\
\hline & $\begin{array}{c}\text { Costal Manual } \\
\text { PJH }\end{array}$ & $1 / \mathrm{H} \mathrm{C}-0$ & $241-517$ & - & 543 & 0,90 \\
\hline $\operatorname{Cos}$ & stal motorizado PL-45 & Pastilha dosadora lilás & - & - & 333 & 0,55 \\
\hline 3 & Arbus $400^{(1)}$ & 16/HC-02 & 276 & 4,0 & 542 & 0,79 \\
\hline 4 & Arbus 400 & 16/HC-02 & 414 & 4,0 & 617 & 0,90 \\
\hline 5 & Arbus 400 & 16/JA-2 & 621 & 4,0 & 521 & 0,76 \\
\hline 6 & Arbus 400 & 16/JA-2 & 1035 & 4,0 & 686 & 1,00 \\
\hline \multirow[t]{2}{*}{7} & Arbus $400+$ pistola & 10/JA-2 & 621 & 4,0 & 429 & 0,76 \\
\hline & pulv. AA2A-AL & 1/AY-SS20 & 690 & 4,0 & 200 & 2,00 \\
\hline
\end{tabular}

$\left({ }^{1}\right)$ Equipamento acoplado ao engate 3 pontos de um trator Valmet 685 , trabalhando a $1.800 \mathrm{rpm}$ em segunda marcha reduzida.

As pulverizações foram realizadas com solução aquosa traçadora, constituída pelo pigmento fluorescente Saturn Yellow $(0,15 \% \mathrm{p} / \mathrm{v})$, solubilizado com o lignosulfonato Vixilperse $(0,015 \% \mathrm{p} / \mathrm{v})$ mais o corante alimentício Azul Brilhante $\left(\mathrm{FD} \& \mathrm{C} n .^{\circ} 1\right)$ à concentração de $0,15 \%(\mathrm{p} / \mathrm{v})$. Utilizou-se essa solução traçadora pela possibilidade de avaliação qualitativa e quantitativa simultânea, sem interferência nas propriedades físico-químicas da calda ou perda de fluorescência (PALLADINI, 2000).

As condições ambientais, no momento das aplicações, foram registradas com auxílio de termohigrômetro (Modelo HT-3003) e anemômetro (Modelo AM-4201), ambos da marca Lutron, posicionados a 2 $\mathrm{m}$ de altura da superfície do solo.
Para avaliar a distribuição da pulverização, realizada com o uso de papel hidrossensível ( 76 × 26 $\mathrm{mm}$ ), as plantas-alvo foram divididas em setor de amostragem superior e inferior. Em cada setor selecionou-se previamente um ramo, posicionado frontalmente à pulverização (perpendicular ao deslocamento do pulverizador) e, ao centro desse ramo, foi instalado um anel de polietileno onde se fixou uma unidade do papel hidrossensível, mantido na posição frontal em relação à pulverização.

Após a aplicação da solução traçadora, os papéis foram retirados das plantas e mantidos em recipiente com isolamento térmico. Posteriormente, foram encaminhados ao laboratório para proceder a análise da densidade das gotas, com o auxílio do software e-Sprinkle (EMBRAPA, 2000). 
Na aplicação do ethephon é fundamental que todos os frutos recebam a quantidade necessária de produto para se obter uniformidade de maturação. Assim, na época da aplicação da calda traçadora, elaborou-se uma escala de notas para possibilitar a análise dos diferentes níveis de cobertura da pulverização dos frutos. Essa escala consta dos valores 0, 1, 2, 3 e 4 que correspondem, respectivamente, à ausência de gotas, $25 \%, 50 \%, 75 \%$ e $100 \%$ da área dos frutos com depósitos, o que possibilitou a avaliação visual dos níveis de depósitos, separadamente, para as áreas dos frutos expostas à pulverização e opostas a ela.

A avaliação, em laboratório, foi feita pela visualização do traçador fluorescente, em ambiente escuro, sob luz ultravioleta (BL 15 BLB). As notas atribuídas à cobertura da pulverização foram submetidas a análise de variância não paramétrica, pelo teste de Wilcoxon a 5\% (ZAR, 1996).

Visando complementar as avaliações visuais, efetuou-se a análise quantitativa dos depósitos. Para isso, colheram-se, dos ramos marcados nos setores superior e inferior, 20 frutos posicionados internamente à copa, os quais, após a pulverização, foram colocados em sacos de polietileno identificados.

À cada amostra, adicionaram-se $20 \mathrm{~mL}$ de água destilada, mantendo-a sob agitação por 30 segundos para a remoção do corante Azul Brilhante. A solução resultante foi colocada em vidros e mantida sob refrigeração $\left(8 \pm 3{ }^{\circ} \mathrm{C}\right)$. Após esse procedimento foi quantificado os depósitos em espectrofotômetro UV-VIS marca GMB, modelo Cintra 20, lendo-se a absorbância a $630 \mathrm{~nm}$.

Os valores de absorbância, quando relacionados a diferentes concentrações do corante Azul Brilhante, permitem o estabelecimento de uma equação de reta linear $\left(R^{2}=0,9964\right)$, indicando a concentração do corante $\left(\mathrm{mg} . \mathrm{L}^{-1}\right)$ capturado pelo alvo durante a aplicação. Ao correlacionar a concentração do corante, na solução de lavagem das amostras, com a obtida na calda de pulverização foi possível estabelecer o volume capturado pelo alvo através da seguinte equação $\left(E_{1}\right)$ :

$$
\mathrm{C}_{\mathrm{i}} \times \mathrm{V}_{\mathrm{i}}=\mathrm{C}_{\mathrm{f}} \times \mathrm{V}_{\mathrm{f}}
$$

Em que: $C_{i}=$ concentração do corante na calda aplicada (1.500 mg. $\left.\mathrm{L}^{-1}\right) ; \mathrm{V}_{\mathrm{i}}=$ volume capturado pelo alvo $(\mathrm{mL}) ; \mathrm{C}_{\mathrm{f}}=$ concentração do corante na amostra, detectada pelo espectrofotômetro em absorbância e transformada para mg. $\mathrm{L}^{-1} ; \mathrm{V}_{\mathrm{f}}=$ volume de diluição da amostra $(20 \mathrm{~mL})$. Os valores dos depósitos foram submetidos à análise de variância, pelo teste $\mathrm{F}$ e as médias comparadas em esquema fatorial $7 \times 2$ (sete equipamentos e duas posições de amostragem) pelo teste de Tukey a $5 \%$.
O Experimento 2 foi implantado no delineamento inteiramente casualizado, com oito tratamentos: sete descritos no Experimento 1 (Tabela 1) mais testemunha e dez repetições, utilizando-se 93,6 mL de ethephon (130 mL de Ethrel 720) em 100 $\mathrm{L}$ de água, aplicado em frutos fisiologicamente maduros.

As mesmas parcelas estabelecidas para avaliação das pulverizações (Experimento 1) foram utilizadas para este propósito, mais uma parcela testemunha. As repetições constituíram-se de cinco plantas consecutivas na linha de plantio, pulverizada de ambos os lados, e as avaliações realizadas em uma só planta, previamente identificada. Após a colheita dos frutos, feita em duas etapas, aos 32 e 59 dias após a aplicação (DAA), efetuou-se a contagem de frutos verdes e maduros (coco + cereja) contidos em um litro (aproximadamente $620 \mathrm{~g}$ ou 720 frutos). Os dados, expressos em porcentagem de frutos verdes e maduros, foram submetidos à análise de variância e as médias comparadas pelo teste de Tukey a $5 \%$.

\section{RESULTADOS E DISCUSSÃO}

As condições ambientais registradas durante as aplicações da solução traçadora (Experimento 1) e do ethephon (Experimento 2) podem ser observadas nas Tabelas 2 e 3 , respectivamente. Verifica-se que, em determinados momentos, a temperatura e a umidade relativa do ar estiveram próximas aos limites aceitáveis $\left(30^{\circ} \mathrm{C}\right.$ e $\left.55 \%\right)$, embora não tenha influenciado diretamente nos resultados do Experimento 1.

Com relação ao Experimento 2, as baixas temperaturas registradas, poderiam ocasionar atraso no efeito do produto, porém, esse efeito também deveria ocorrer, ainda que em menor intensidade, nas plantas não tratadas, devido à presença do etileno endógeno. Entretanto, pelo fato de a colheita ter sido realizada aos 32 e 59 dias após a aplicação (DAA), esse efeito pode assumir menor importância, pois o período de colheita ultrapassou 30 DAA, tempo necessário para garantir a uniformidade de maturação dos frutos, conforme constatado por Miguel et al. (1975) e WINSTON et al. (1992).

Maior densidade de gotas foi obtida na pulverização com o equipamento Arbus 400, pontas JA-2 a $621 \mathrm{kPa}$ (tratamento 5), na parte inferior da planta, mesmo não sendo esse o tratamento com maior volume de calda. Nota-se, ainda, que os tratamentos 5 e 6, quando se empregou o Arbus 400 e, em ambos utilizando a ponta JA-2, mas em pressões diferentes, destacaram-se, obtendo maior densidade de gotas nessa posição de amostragem em relação aos demais. Por outro lado, no tratamento 1 , quando se empregou o pulverizador costal manual $\mathrm{PJH}$, constatou-se menor número médio de gotas por $\mathrm{cm}^{2}$ (Tabela 4 ). 
Tabela 2. Condições meteorológicas no momento das aplicações do traçador Azul Brilhante em 24/5/2001, com diferentes equipamentos na cultura do café

\begin{tabular}{lcccc}
\hline Tratamento & Horário & Temperatura & UR & Vento \\
\hline & & ${ }^{\circ} \mathrm{C}$ & $\%$ & $\mathrm{~km} \cdot \mathrm{h}^{-1}$ \\
1 & $16: 25$ & 23,7 & 57,4 & $5,5-7,0^{(1)}$ \\
2 & $16: 35$ & 23,0 & 60,0 & $4,0-6,5$ \\
3 & $11: 00$ & 22,5 & 61,6 & $3,5-6,5$ \\
4 & $11: 30$ & 24,3 & 59,3 & $5,6-7,2$ \\
5 & $11: 40$ & 23,9 & 58,0 & $6,2-7,5$ \\
6 & $11: 50$ & 26,0 & 53,2 & $6,2-7,5$ \\
$7^{(2)}$ & $16: 05$ & 23,6 & 56,8 & $6,3-7,6$ \\
& $16: 15$ & 23,8 & 57,7 & $6,5-9,0$ \\
\hline
\end{tabular}

( $\left.{ }^{1}\right)$ Velocidade do vento medida a 2,0 m de altura do solo.

$\left({ }^{2}\right)$ Valores referentes à aplicação com equipamento Arbus 400 e com pistola pulverizadora respectivamente.

Tabela 3. Condições meteorológicas no momento das aplicações de ethephon em 22/6/2001, com diferentes equipamentos na cultura do café

\begin{tabular}{lcccc}
\hline Tratamento & Horário & Temperatura & UR & Vento \\
\hline & & ${ }^{\circ} \mathrm{C}$ & $\%$ & $\mathrm{~km} \cdot \mathrm{h}^{-1}$ \\
1 & $17: 40$ & 6,6 & 85,7 & $0,0^{(1)}$ \\
2 & $17: 50$ & 6,0 & 89,6 & 0,0 \\
3 & $17: 30$ & 7,6 & 83,2 & 0,0 \\
4 & $17: 35$ & 7,1 & 84,2 & 0,0 \\
5 & $17: 15$ & 10,4 & 70,1 & 0,0 \\
6 & $17: 20$ & 9,7 & 74,7 & 0,0 \\
$7^{(2)}$ & $17: 10$ & 11,8 & 63,4 & 0,0 \\
& $17: 00$ & 12,8 & 56,0 & 0,0 \\
\hline
\end{tabular}

$\left({ }^{1}\right)$ Velocidade do vento medida a 2,0 m de altura do solo.

$\left({ }^{2}\right)$ Valores referentes à aplicação com equipamento Arbus 400 e com a pistola pulverizadora respectivamente.

Tabela 4. Densidade média das gotas $\left(n .^{\circ}\right.$ médio de gotas $\left./ \mathrm{cm}^{2}\right)$ em papel hidrossensível, analisados através do software e-Sprinkle, nas partes superior e inferior de plantas de cafeeiro

\begin{tabular}{|c|c|c|}
\hline Tratamento & Parte superior & Parte inferio \\
\hline & 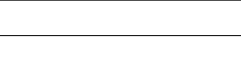 & \\
\hline 1 & 44,2 & 32,1 \\
\hline 2 & 85,4 & 156,3 \\
\hline 3 & 51,2 & 187,6 \\
\hline 4 & 31,4 & 140,1 \\
\hline 5 & 30,2 & 229,9 \\
\hline 6 & 63,0 & 217,5 \\
\hline 7 & 22,3 & 83,5 \\
\hline
\end{tabular}


Com exceção do tratamento 1 , nos demais tratamentos a densidade de gotas foi muito maior na parte inferior da planta, obtendo-se com Arbus 400 e pontas JA-2 a $621 \mathrm{kPa}, 7,6$ vezes mais depósito na parte inferior do que na superior.

A análise quantitativa do traçador mostrou haver interação entre os fatores em estudo e os níveis de depósitos em frutos de cafeeiro (Tabela 5). Evidenciam-se, também, maiores depósitos da solução traçadora nos tratamentos que utilizaram o pulveri- zador Arbus 400, independentemente da ponta e do volume de aplicação, exceto no tratamento envolvendo esse equipamento associado à pistola pulverizadora, que obteve níveis intermediários de depósitos.

Os maiores depósitos revelam que a assistência de ar foi fundamental para a obtenção de maiores depósitos nos frutos do cafeeiro. Ressalte-se a pequena deposição quando foram utilizados equipamentos portáteis, em relação aos de tração mecânica.

Tabela 5. Efeito de diferentes tratamentos e posições de amostragem sobre o depósito do traçador Azul Brilhante em frutos de cafeeiro

\begin{tabular}{lcc}
\hline Fatores de variação & Graus de liberdade & Valores de F e médias de depósito (mL/amostra) \\
\hline Tratamento (T) & 6 & $6,2456^{*}$ \\
Posição (P) & 2 & $55,0004^{*}$ \\
$(\mathrm{~T}) \times(\mathrm{P})$ & 6 & $2,9059^{*}$ \\
\hline $\mathrm{CV}(\%)$ & 59,26 \\
\hline Médias (mg.L $\left.{ }^{-1}\right)$ & \\
\hline 1 & & $0,4944 \mathrm{c}$ \\
2 & $0,7501 \mathrm{bc}$ \\
3 & $1,6868 \mathrm{a}$ \\
4 & $1,6513 \mathrm{a}$ \\
5 & $1,3983 \mathrm{ab}$ \\
6 & $1,5876 \mathrm{a}$ \\
7 & $1,2586 \mathrm{abc}$ \\
\hline DMS (5\%) & 0,7928 \\
\hline Superior & $0,7373 \mathrm{~b}$ \\
Inferior & $1,7847 \mathrm{a}$ \\
\hline DMS (5\%) & 0,2797 \\
\hline
\end{tabular}

* = significativo a $5 \%$ de probabilidade.

Médias na mesma coluna e dentro do mesmo fator, com a mesma letra, não diferem entre si pelo teste de Tukey a $5 \%$.

O desmembramento da interação entre os fatores em estudo permitiu identificar interferência do tratamento em relação à posição de amostragem, principalmente na parte inferior da planta, onde os depósitos nos tratamentos com assistência de ar (tratamentos 3, 4, 5 e 6) foram significativamente superiores em relação aos obtidos com os equipamentos portáteis (Tabela 6).

Esse fato foi, também, observado por Duarte et al. (1977), que constataram menor cobertura da par- te alta das plantas de cafeeiro quando utilizaram equipamentos de tração mecânica.

Pode-se, ainda, constatar que, nos tratamentos onde utilizaram equipamentos portáteis, embora a quantidade depositada tenha sido inferior, a distribuição nas diferentes posições da planta foi mais homogênea (Tabela 6), se comparada com os demais tratamentos. Esse fato indica certa deficiência do equipamento de tração mecânica, que aplica maior volume de produto na parte inferior das plantas de café. 
Tabela 6. Efeito do tratamento sobre a posição de amostragem nos depósitos (mL) de corante Azul Brilhante em frutos de cafeeiro

\begin{tabular}{lrr}
\hline Tratamento/posição & Parte superior & Parte inferior \\
\hline & & $(\mathrm{mL})$ \\
\cline { 2 - 3 } 2 & 0,4259 a A & 0,5630 b A \\
2 & 0,4868 a A & 1,0134 b A \\
3 & 0,9491 a A & 2,4245 a B \\
4 & 0,7123 a A & 2,5904 a B \\
5 & 0,6600 a A & 2,1366 a B \\
6 & 0,9538 a A & 2,2214 a B \\
7 & 0,9738 a A & 1,5435 ab A \\
\hline
\end{tabular}

Médias seguidas pela mesma letra minúscula na coluna e pela mesma letra maiúscula na linha, não diferem entre si pelo teste de Tukey a $5 \%$ de probabilidade.

A Figura 1 mostra que maiores freqüências de ausência de gotas e 25\% de deposição nos frutos (notas zero e 1) ocorreram na superfície oposta dos frutos à pulverização e, nesse mesmo local, observou-se pequena deposição com pouca ou nenhuma freqüência dos frutos com 50\%, 75\% e 100\% de deposição (notas 2,3 e 4). Com relação à superfície dos frutos diretamente exposta à pulverização, na parte inferior das plantas, observaram-se maiores freqüências das notas 2, 3 e 4, com destaque para a nota 4, com valores próximos a $50 \%$ da freqüência. Verificou-se, também, que praticamente não houve nota zero para os frutos expostos à pulverização e posicionados na parte inferior das plantas.

Assim como na quantificação dos depósitos, pode-se observar pela Tabela 7 melhores níveis de cobertura dos frutos na parte inferior da planta, demonstrando haver coerência entre as informações obtidas com os diferentes métodos de avaliação. Podese constatar, ainda, que não houve diferença significativa entre os tratamentos, independentemente da posição de amostragem.

Tabela 7. Efeito do tratamento e dos setores de amostragem sobre a cobertura do pigmento fluorescente Saturn Yellow (IE - posição inferior e região exposta dos frutos à pulverização; IO - posição inferior e região oposta dos frutos à pulverização; SE - posição superior e região exposta; SO - posição superior e região oposta)

\begin{tabular}{|c|c|c|c|c|}
\hline Tratamentos & IE & $\mathrm{IO}$ & SE & $\mathrm{SO}$ \\
\hline 1 & $252 \mathrm{a}$ & 183 a & $140 \mathrm{a}$ & $179 a$ \\
\hline 2 & $177 \mathrm{a}$ & $155 \mathrm{a}$ & $195 \mathrm{a}$ & $206 a$ \\
\hline 3 & $222 \mathrm{a}$ & $265 a$ & $267 \mathrm{a}$ & $234 a$ \\
\hline 4 & $269 \mathrm{a}$ & $293 a$ & $213 \mathrm{a}$ & $206 a$ \\
\hline 5 & 241 a & 305 a & 231 a & $247 \mathrm{a}$ \\
\hline 6 & $271 \mathrm{a}$ & $210 \mathrm{a}$ & 298 a & $261 \mathrm{a}$ \\
\hline 7 & $162 \mathrm{a}$ & $183 \mathrm{a}$ & 249 a & $261 \mathrm{a}$ \\
\hline Posições & \multicolumn{2}{|c|}{ Exposta à pulverização } & \multicolumn{2}{|c|}{ Oposta à pulverização } \\
\hline Superior & \multicolumn{2}{|c|}{$2266 \mathrm{~B}$} & \multicolumn{2}{|c|}{3191 A } \\
\hline Inferior & \multicolumn{2}{|c|}{$4062 \mathrm{~A}$} & \multicolumn{2}{|c|}{3137 A } \\
\hline
\end{tabular}

Médias seguidas de mesma letra, na coluna, não diferem entre si pelo Teste de Wilcoxon a 5\%. 


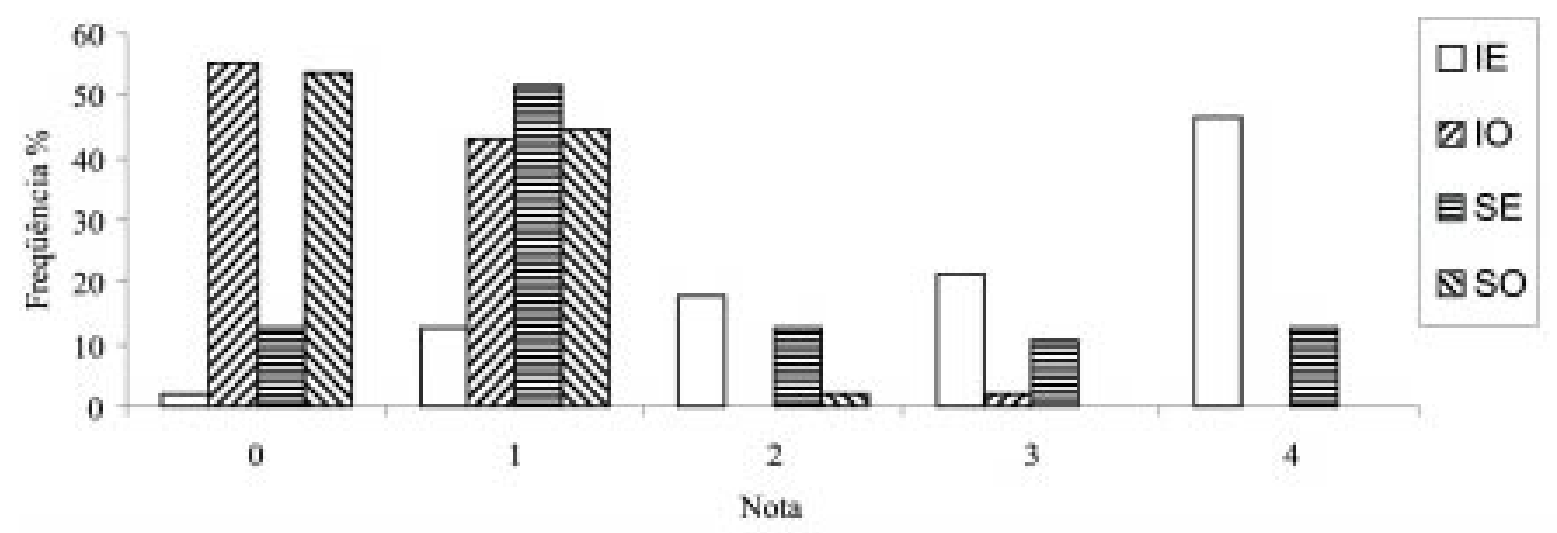

Figura 1. Freqüência de notas (\%) nas diferentes posições de amostragem de plantas de cafeeiro, sendo: IE - posição inferior e região exposta dos frutos à pulverização; IO - posição inferior e região oposta dos frutos à pulverização; SE - posição superior e região exposta; SO - posição superior e região oposta.

Ao comparar o efeito do tratamento sobre a distribuição da pulverização, na face exposta dos frutos da parte inferior da planta (Figura 2), nota-se a ausência de nota zero e a ocorrência de nota 4 em todos os tratamentos, destacando-se as configurações sob maiores pressões (tratamentos 4, 5 e 6). Provavelmente, se deve às gotas menores nessas configurações. Segundo o fabricante, o diâmetro mediano volumétrico (DMV) das gotas com as pontas HC-02 à $414 \mathrm{kPa}$ é $131 \mu \mathrm{m}$ e JA-2 à pressão de 517 e $1.035 \mathrm{kPa}$ são 88 e $78 \mu \mathrm{m}$ respectivamente (JАСТО, 2000).

Na mesma posição da planta, mas na superfície do fruto oposta à pulverização (Figura 3) verifica-se que a freqüência da ausência de gotas (nota zero) superou $80 \%$ para o tratamento 2 e manteve-se acima de $60 \%$ nos tratamentos 1 e 7 . A utilização de equipamento com assistência de ar foi fundamental para a melhoria da pulverização, possibilitando $25 \%$ de cobertura (nota 1 ) em mais de $40 \%$ dos frutos.

Aos 32 DAA, o ethephon proporcionou aumento significativo na porcentagem de maturação dos frutos e diminuição da proporção de grãos verdes, exceto para frutos pulverizados com o equipamento Arbus 400 combinado à pistola de pulverização (tratamento 7), quando os valores não diferiram estatisticamente dos frutos não tratados (Tabela 8).

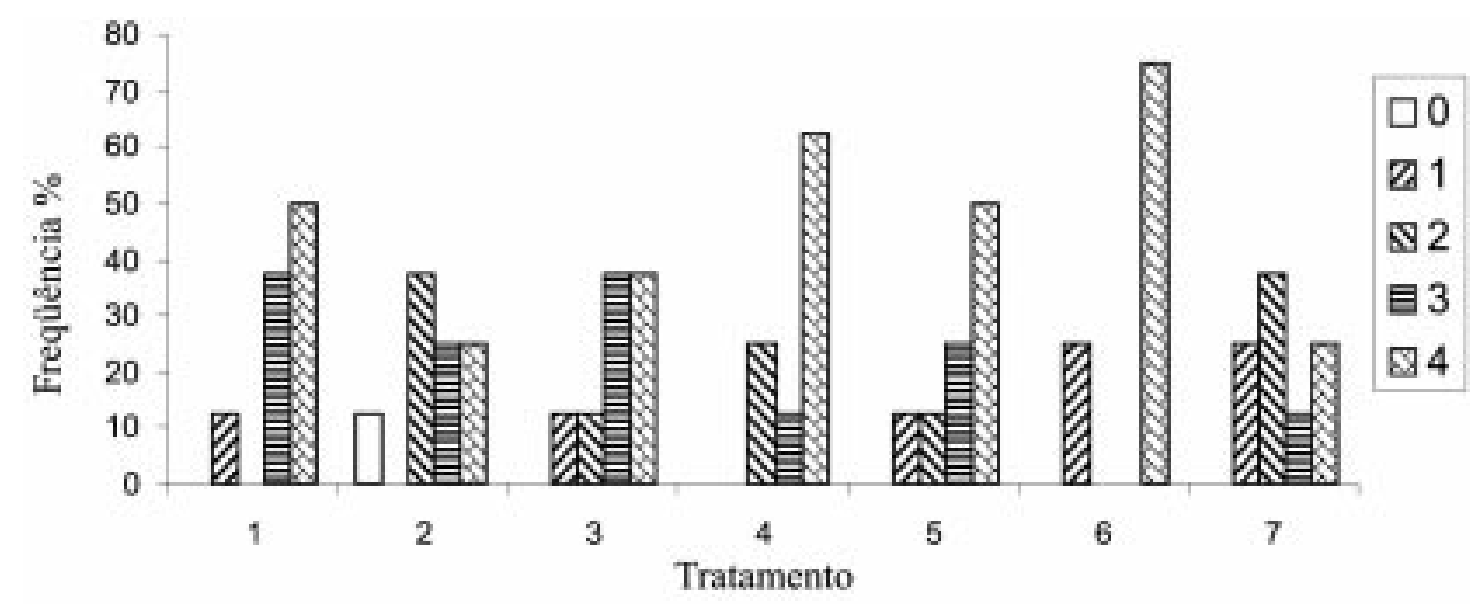

Figura 2. Freqüência de notas nos diferentes tratamentos na posição IE (posição inferior da planta e região exposta dos frutos à pulverização). 


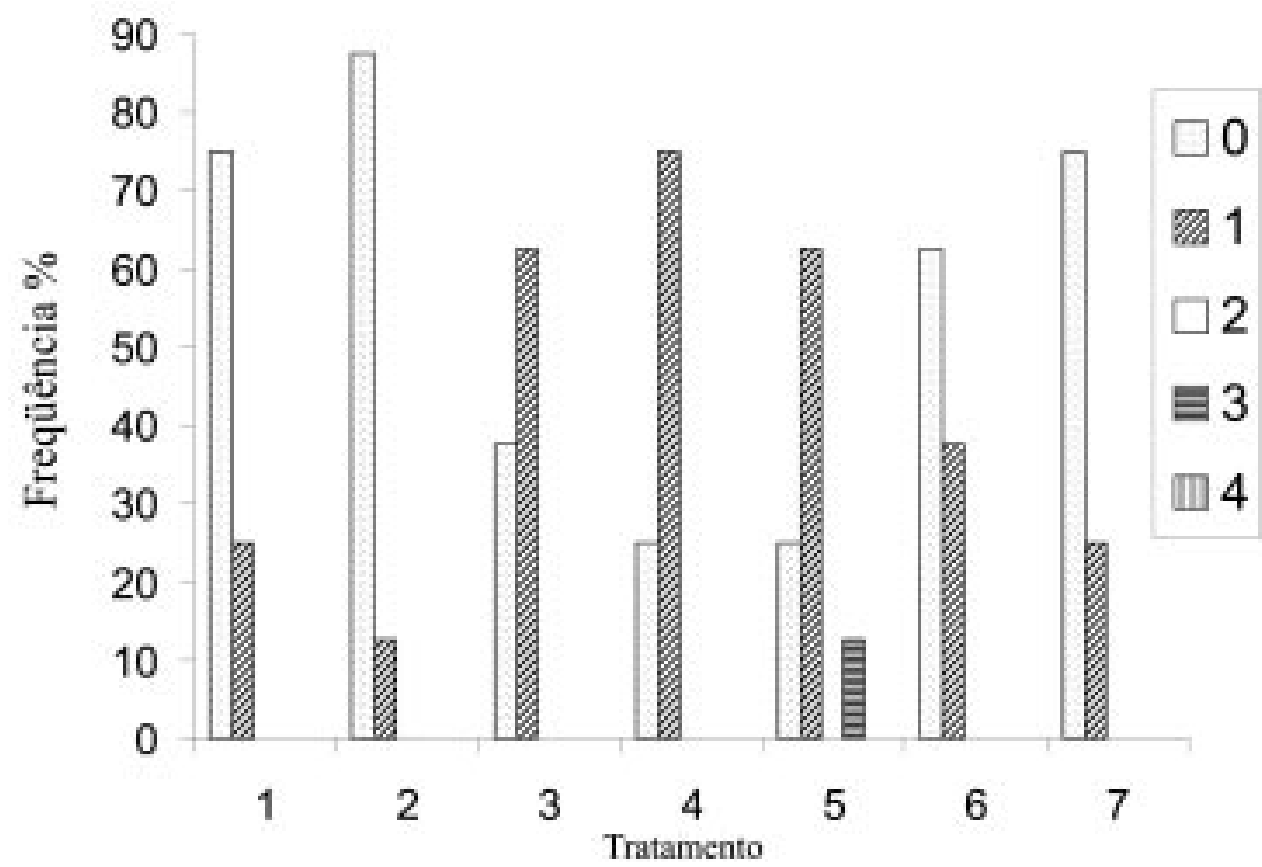

Figura 3. Freqüência (\%) de notas nos diferentes tratamentos na posição inferior da planta e região oposta à pulverização.

Tabela 8 - Porcentagem de frutos verdes, cereja e maduros, aos 32 e 59 dias após a aplicação de ethephon, com diferentes equipamentos e condições operacionais

\begin{tabular}{|c|c|c|c|c|c|c|}
\hline \multirow{2}{*}{ Tratamento } & \multicolumn{3}{|c|}{$32 \mathrm{DAA}$} & \multicolumn{3}{|c|}{59 DAA } \\
\hline & Verdes & Cereja & Maduros* & Verdes & Cereja & Maduros* \\
\hline & & & 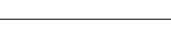 & & & 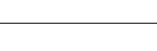 \\
\hline 1 & 45,12 bc & $41,77 \mathrm{ab}$ & $54,88 \mathrm{ab}$ & $30,07 \mathrm{bc}$ & $31,21 \mathrm{c}$ & $69,93 \mathrm{ab}$ \\
\hline 2 & $45,63 \mathrm{bc}$ & $41,46 \mathrm{ab}$ & $54,37 \mathrm{ab}$ & $41,66 \mathrm{~b}$ & $29,41 \mathrm{~cd}$ & $58,34 \mathrm{~b}$ \\
\hline 3 & $38,75 \mathrm{c}$ & 51,86 a & $61,25 \mathrm{a}$ & $21,37 \mathrm{c}$ & $34,25 \mathrm{bc}$ & 78,63 a \\
\hline 4 & $36,94 \mathrm{c}$ & $53,55 \mathrm{a}$ & $63,07 \mathrm{a}$ & $26,64 \mathrm{bc}$ & $40,28 \mathrm{ab}$ & $73,36 \mathrm{ab}$ \\
\hline 5 & $47,74 \mathrm{bc}$ & $43,39 \mathrm{ab}$ & $52,26 \mathrm{ab}$ & $29,87 \mathrm{bc}$ & $39,31 \mathrm{ab}$ & $70,13 \mathrm{ab}$ \\
\hline 6 & $48,63 \mathrm{bc}$ & $45,75 \mathrm{ab}$ & $51,37 \mathrm{ab}$ & $30,18 \mathrm{bc}$ & $44,34 \mathrm{a}$ & $69,82 \mathrm{ab}$ \\
\hline 7 & $58,36 \mathrm{ab}$ & $35,24 \mathrm{bc}$ & $41,64 \mathrm{bc}$ & $34,40 \mathrm{bc}$ & $32,85 \mathrm{bc}$ & $65,60 a b$ \\
\hline Testemunha & $70,09 a$ & $23,71 \mathrm{c}$ & $29,91 \mathrm{c}$ & $63,73 \mathrm{a}$ & $22,00 \mathrm{~d}$ & $36,87 \mathrm{c}$ \\
\hline Dms & 18,87 & 13,98 & 18,87 & 17,47 & 8,05 & 17,43 \\
\hline CV (\%) & 18,82 & 16,20 & 18,01 & 24,54 & 11,48 & 13,01 \\
\hline
\end{tabular}

Médias seguidas de mesma letra, na coluna, não diferem entre si pelo Teste de Tukey a 5\% de probabilidade.

${ }^{*}=\%$ de grãos maduros $=$ somatório dos grãos em coco e cereja.

A eficiência dos tratamentos 3 e 4 merece destaque, embora não foram as melhores nos indicativos relacionados à uniformidade de distribuição da pulverização na planta, proporcionaram aumento na porcentagem de grãos maduros e cereja, em mais de duas vezes em relação à testemunha, conseguindo também diminuir, em quase a metade, a porcentagem de grãos verdes.

Fato semelhante ocorreu aos 59 DAA, quando nos tratamentos 3 e 4 foram obtidas as menores porcentagens de frutos verdes e as maiores de maduros (Tabela 8). 
No geral, à exceção do tratamento 7 (Arbus 400 mais pistola pulverizadora), todos os demais proporcionaram redução significativa na porcentagem de grãos verdes e aumento de cereja e maduros, tanto aos 32 quanto aos 59 DAA, demonstrando interferência positiva do produto na maturação dos frutos do cafeeiro e do equipamento utilizado para a aplicação do produto.

Por outro lado, aos 32 DAA, não houve diferença entre os tratamentos quanto à porcentagem de grãos verdes, cereja e maduros.

Relatos na literatura sugerem que a colheita seja realizada aos 30 DAA do ethephon (Miguel et al., 1975; TEIXEIRA et al., 1975; Winston et al., 1992). Entretanto, neste experimento, provavelmente devido à interferência das condições climáticas na eficiência do ethephon, a porcentagem de frutos verdes mantevese elevada, tanto aos 32 quanto aos 59 DAA. Esse fato não invalida ou diminui a importância das informações aqui obtidas, pois as condições climáticas interferem na maturação dos frutos de todas as plantas, não somente daquelas tratadas com o produto. Além disso, a análise estatística mostrou haver diferenças na maturação dos frutos, indicando a eficiência da realização desse procedimento, principalmente quando se aplicou o ethephon com o equipamento Arbus 400, equipado com pontas HC-02 e volumes variando de 542 a 617 L.ha $^{-1}$.

Finalmente, é importante ressaltar a existência de número bem reduzido de trabalhos na literatura que se referem às técnicas de aplicação e ao uso de ethephon em cafeeiro; ademais, a grande maioria dos trabalhos consultados são publicados sob a forma de resumo, envolvendo equipamentos de aplicação muito diferentes dos comercializados atualmente, fato que impossibilita a comparação e o confronto dos dados aqui obtidos com outros trabalhos.

\section{CONCLUSÕES}

1. Melhor deposição nas plantas de café foi conseguida com equipamentos dotados de assistência de ar;

2. Equipamentos costais não mostraram bom desempenho na aplicação do regulador de crescimento ethephon em cafeeiro;

3. A associação de equipamento mecanizado com pistola pulverizadora resultou em diminuição na deposição;
4. O ethephon foi eficiente na maturação dos frutos do cafeeiro, diminuindo a porcentagem de grãos verdes e aumentando a de cereja e maduros.

5. Há necessidade de melhor adaptação do pulverizador mecanizado a fim de tornar a distribuição dos depósitos mais homogênea na parte superior e na inferior das plantas de cafeeiro.

\section{AGRADECIMENTOS}

À Fundação de Amparo a Pesquisa do Estado de São Paulo pela Bolsa de Iniciação Científica e a Carlos Renato Alves Ragoso que, gentilmente, ofereceu a Fazenda Três Irmãos (Botucatu) para a realização dos experimentos.

\section{REFERÊNCIAS}

CRISOSTO, C.H.; GRANTZ, D.A.; OSGOOD, R.V.; CID, L.R. Synchronization of fruit ripening in coffee with low concentrations of ethephon. Postharvest Biology and Technology, v.1, n.4, p.371-378, 1992.

DUARTE, C.S.; FAQUIN,W; SALGADO, A .R., Eficiência do Ethrel (Ácido 2-cloroetil fosfônico) na maturação de café, sob diferentes formas de aplicação. In: CONGRESSO BRASILEIRO DE PESQUISAS CAFEEIRAS, 5.,1977, Guarapari. Resumos... Rio de Janeiro: IBC/GERCA, 1977. p.149-151.

EMPRESA BRASILEIRA DE PESQUISA AGROPECUÁRIA. Sofware e-Sprinkle: sadgna. v.10, São Carlos, 2000. CD-ROM.

JACTO. Bicos Série J.A.. Pompéia: Máquinas Agrícolas Jacto S/A., 2000. 2p. (Folheto informativo)

KASHIMA, T; HONDA, A.I.; FAVA, J.F.M.; BASTOS, M.V.; SARTORI, S. A colheita mecânica do café. In: RENA, A.B.; MALAVOLTA, E.; ROCHA, M.; YAMADA, T. (Eds.) Cultura do cafeeiro: fatores que afetam a produtividade. Piracicaba: Potafos, 1986, p.409-422.

MIGUEL, A.E.; MATIELLO, J.B.; SILVA, J.B.S.; ALVARENGA, G. Estudo da época $x$ dosagem de aplicação de Ethrel em cafeeiros. In: CONGRESSO BRASILEIRO DE PESQUISAS CAFEEIRAS, 3., 1975, Curitiba. Resumos... Rio de Janeiro: IBC/ GERCA, 1975. p.262-269.

MONACO, L.C.; SÖNDAHL, M.R. Emprego de etileno na maturação de frutos de café. Pesquisa Agropecuária Brasileira, Brasília, v. 9, p.135-137, 1974.

OZEKI, Y.; KUNZ, R.P. Manual de aplicação aérea. São Paulo: Ciba Agro, s.d.46 p. 
PALLADINI, L.A. Metodologia para avaliação da deposição em pulverizações. 2000. 111f. Tese (Doutorado em Agronomia/Proteção de Plantas) - Faculdade de Ciências Agronômicas, Universidade Estadual Paulista, Botucatu.

QUAGGIO, J.A.; DUARTE, G.S.; HOSTALACIO, S.; RIOS, J.M.C. Efeito da concentração e da época de aplicação do Ethrel (ácido 2-cloroetil-fosfônico) na maturação e na abscisão de frutos e folhas do cafeeiro, variedade Mundo Novo. In: CONGRESSO BRASILEIRO DE PESQUISAS CAFEEIRAS, 4., 1976, Caxambu. Resumos... Rio de Janeiro: IBC/GERCA, 1976. p.208-209.

RENA, A.B.; MAESTRI, M. Fisiologia do cafeeiro. In: RENA, A.B.; MALAVOLTA, E.; ROCHA, M.; YAMADA, T. (Eds.). Cultura do cafeeiro: fatores que afetam a produtividade. Piracicaba: Potafos, 1986. p.13-86.

SONDAHL, M.R.; TEIXEIRA, A. A.; FAZUOLI, L.C.; MONACO, L.C. Efeito do etileno sobre o tipo e qualidade da bebida de café. Turrialba, San Jose, v. 24, n.1, p.17-19, 1974.
TEIXEIRA, A.A.; MATIELLO, J.B.; MIGUEL, A.E.; SILVA, J.B.S.; PAULINO, A.J.; JORGE, J.P.M. Observações preliminares sobre o efeito do Ethrel na qualidade do café. In: CONGRESSO BRASILEIRO DE PESQUISAS CAFEEIRAS, 3., 1975, Curitiba. Resumos... Rio de Janeiro: IBC/GERCA, 1975. p.213-216.

WAREING, P.F.; PHILLIPS, I.D.J. The control of growth and differentiation in plants. Oxford: Pergamon Press, 1970.303p.

WINSTON, E.C.; HOULT, M.; HOWITT, C.J.; SHEPHERD, R.K. Ethylene induced fruit ripening in arabica coffee (Coffea arabica L.). Australian Journal Experimental Agriculture, East Melbourne, v.32, n.3, p.401-408, 1992.

ZAR, J.H. Biostatistical Analysis. 3rd ed. New Jersey: Prentice Hall, 1996. 662p. 